\title{
Immediate and delayed retention, arousal, and the orienting and defensive reflexes'
}

\author{
IRVING MALTZMAN, WILLIAM KANTOR AND BARRY LANGDON \\ UNIVERSITY OF CALIFORNIA, LOS ANGELES
}

Contrary to implications of previous paired-associate learning studies and Walker's theory, high arousal words showed superior immediate as well as delayed retention. GSRs were reliably greater for the high than the low arousal words. High arousal words also evoked reliably greater cephalic vasoconstriction, defensive reflexes, than low arousal words.

Walker (1958) has presented a theory of arousal and trace consolidation implying that stimuli with high arousal value will show poorer immediate retention and superior delayed retention than stimuli with low arousal value. Results of paired-associate studies support this implication (Kleinsmith \& Kaplan, 1963, 1964; Walker \& Tarte, 1963).

However, the theoretical implications of the above studies are of questionable generality for two reasons. First, these paired-associate studies confound the effects of arousal during learning and retention, since the stimulus words, high or low arousal are presented as cues in the retention test as well as in the single learning trial. Second, physiological data is accumulating which indicate that the concept of nonspecific arousal based upon activity of the brain stem reticular activating system is greatly oversimplified (e.g., Anokhin, 1961).

The purpose of this study was to employ a performance task less complex than the previously employed pairedassociate situation, and to employ measures of the orienting (OR) and defensive (DR) reflexes (Sokolov, 1963) in studing the physiological reactions to words. Method

Eighty students from introductory psychology classes, 40 men and 40 women, served as Ss. Eight high arousal and eight low arousal words (Walker \& Tarte, 1963) were used in two counterbalanced lists of 16 words each prepared in a prearranged random order and recorded on magnetic tape. The interword interval was $10 \mathrm{sec}$. An equal number of men and women received one of the two counterbalanced lists via earphones following instructions that they were participating in a study of the physiological correlates of relaxation. No mention was made of a subsequent retention test. Palmer GSR was recorded along with cephalic vasomotor activity. The latter was recorded by means of a photoplethysmograph taped to the forehead in the region of the left temporal artery and held in place by means of an adjustable head band.

Half the Ss were asked to write down as many of the words as they could remember immediately after the tape recording was completed and the transducers removed. Prior to their retention test the remaining Ss were administered the non-verbal Abstract Reasoning Test of the Differential Aptitudes Test Battery which required one-half hour.

\section{Resulis}

The mean numbers of low arousal words recalled in the immediate and delayed retention test were 3.15 and 2.62, respectively. For high arousal words the respective immediate and delayed retention means were 5.82 and 4.50. An analysis of variance indicated that immediate retention was reliably superior to delayed retention $(F=15.50, d f=1 / 64)$, and that reliably more high than low arousal words were recalled $(F=119.41, \mathrm{df}=1 / 64)$. The interaction between type of word and retention interval, which was in the direction opposite to that predicted by Walker's theory, was not significant $(\mathrm{F}=3.69, \mathrm{df}=1 / 64)$. High arousal words evoked reliably larger GSRs (log conductance change scores) than low arousal words, 1.01 vs. $.67(\mathrm{~F}=74.84$, $\mathrm{df}=1 / 64$ ). Trends for the two kinds of words also differed reliably. Of theoretical importance is that the GSR to the initial emotional and neutral words did not differ reliably. The reliable difference between the two kinds of words developed during the course of word presentations.

Cephalic vasodilation, a measure of the OR, was larger for the high arousal than low arousal words, but the difference was not significant. The trends over words were reliably different $(F=1.45, d f=7 / 448)$. Cephalic vasoconstriction, the measure of the DR, was reliably greater for the high than the low arousal words ( $F=$ 4.23 , $\mathrm{df}=1 / 64)$. The trends over words were also reliably different $(\mathrm{F}=2.03, \mathrm{df}=7 / 448)$.

\section{Discussion}

Results of the verbal retention test indicating reliably superior retention of high than low arousal words with no reliable interaction between retention interval and type of word is contrary to Walker's (1958) theory of action decrement. The reliably greater GSRs evoked by high as compared to low arousal words is in accord with arousal theory, but is equally in accord with an interpretation in terms of the orienting and defensive reflexes (Maltzman \& Raskin, 1965; Sokolov, 1963). The different trends obtained by the two types of words suggests that there were two determiners of the OR. The initial occurrence of the OR to words in the list was primarily a function of "novelty," stimulus change; the words were not anticipated at that particular point in time. Only after several words had been presented 
were words no longer "novel," and importantly, only after Ss learned that some were "emotional" and others "neutral," did different trends appear.

We hypothesize that occurrence of an OR facilitates reception of words and their retention. It is reinforcing per se. However, another possible variable differentially facilitating retention of high arousal words is that they are more readily categorized, labelled as a discrete class, than low arousal words. This in itself may facilitate retention.

Reliably larger cephalic vasoconstriction evoked by high than low arousal words indicates that the former evoked conditioned DRs. An unresolved problem of considerable theoretical importance is the relationship between the OR and DR. Sokolov (1963) suggests that cephalic vasoconstriction is a unique measure of the DR under conditions other than temperature loss. Cephalic vasodilation in turn is a unique measure of the OR. These two peripheral measures are necessarily incompatible. But the status of the GSR is not clear, whether it is a unique measure of the OR or a nonspecific measure that reflects an interaction of ORs and DRs in the same fashion as peripheral vasoconstriction. The present data do not resolve this problem, but we would surmise that the GSR is primarily a measure of the OR, or at least that $O R$ and $D R$ are not always incompatible.

\section{References}

Anokhin, P. K. A new conception of the physiological architecture of conditioned reflex. In J. F. Delafresnaye (Ed.), Brain mechanisms and learning. Oxford: Blackwell, 1961, Pp. 189-229.

Kleinsmith, L. J., \& Kaplan, S. Paired-associate learning as a function of arousal and interpolated interval. J. exp. Psychol., $1963,65,190-193$.

Kleinsmith, L. J., \& Kaplan, S. The interaction of arousal and recall interval in nonsense syllable paired-associate learning. J. exp. Psychol., 1964, 67, 124-126.

Maltzman, I., \& Raskin, D. C. Effects of individual differences in the orienting reflex on conditioning and complex processes. $J$. exp. res. Person., 1965, 1, 1-16.

Sokolov, E. N. Perception and the conditioned reflex. New York: Macmillan, 1963.

Walker, E. L. Action decrement and its relation to learning. Psychol. Rev., 1958, 65, 129-142.

Walker, E. L., \& Tarte, R. D. Memory storage as a function of arousal and time with homogeneous and heterogeneous lists. J. verbal Learn. verbal Behav., 1963, 2, 113-119.

\section{Note}

1. This study was made possible by funds granted by the Carnegie Corporation of New York and PHS Research Grant MH 04684 from the Institute of Mental Health. The statements made and views expressed are solely the responsibility of the authors. Computing assistance was obtained from the Health Sciences Computing Facility, UCLA, sponsored by NIH Grant FR-3. 